\section{Dental Fear in Children: Association with Dental Caries and Molar Incisor Hypomineralization}

Isla Camilla Carvalho Laureano ${ }^{1} \mathbb{D}$, Lunna Farias ${ }^{1} \mathbb{D}^{\mathbb{D}}$, Liege Helena Freitas Fernandes ${ }^{1}\left[{ }^{-}\right.$, Catarina Ribeiro Barros de Alencar ${ }^{2}{ }^{-1}$, Franklin Delano Soares Forte $^{3}$, Daniela Rios Honório ${ }^{4} \mathbb{B}$, Alessandro Leite Cavalcanti ${ }^{1}$ (D)
'Departament of Dentistry, School of Dentistry, UEPB Universidade Estadual da Paraíba, Campina Grande, PB, Brazil ${ }^{2}$ Academic Unit of Biological Sciences, School of Dentistry, UFCG - Universidade Federal de Campina Grande, Patos, PB, Brazil ${ }^{3}$ Department of Clinical and Social Dentistry, School of Dentistry, UFPB - Universidade Federal da Paraíba, João Pessoa, PB, Brazil ${ }^{4}$ Department of Pediatric Dentistry, Orthodontics and Public Health, Bauru School of Dentistry, USP - Universidade de São Paulo, Bauru, SP, Brazil

Correspondence: 1sla Camilla Carvalho Laureano, Avenida das Baraúnas, S/N, 8429-500 Campina Grande, PB, Brasil. Tel: +55-83-99802-4244. e-mail: carvalhoisla@gmail.com

Key Words: dental anxiety, dental caries, dental enamel hypoplasia, child, epidemiology.

\section{Introduction}

Dental fear is an amplified physiological, behavioral and emotional reaction to one or more threatening stimuli in dental practice (1). There is a wide variation in the prevalence of dental fear worldwide identified with rates ranging from $2.4 \%$ in study conducted in the Netherlands (2), to $66.0 \%$ in São Paulo, Brazil (3), and the use of different methodologies for measuring fear, application in different age groups, and different cultural parameters may be responsible for these variations (4).

Dental fear is multifactorial (1) and can be triggered by pain experience $(2,5)$, dental caries $(6)$, negative experiences during dental treatment (7), socioeconomic, psychological (8) and cultural aspects, as well as by the profile of visits to dental services and previous visits to the dentist $(5,8)$. In children with molar incisor hypomineralization (MIH), the risk of developing fear, anxiety and behavioral problems may be increased $(9,10)$, because MIH is associated with many dental problems such as dentin hypersensitivity, rapid development of carious lesions and need for recurrent dental treatment $(9,10)$, as well as dental pain $(10,11)$ and difficulties in obtaining adequate anesthesia (9).

These findings led to the idea of a vicious cycle of fear, in which individuals highly affected by dental fear delay treatment, which leads to the development of more complex diseases, which possibly require more invasive and potentially painful treatments, thus reinforcing or increasing the level of fear (12). Early identification of dental fear in children is essential so that it can be controlled or reduced, and dental treatment can be effective (13).

Few studies have analyzed the relation between dental fear and dental caries in patients with $\mathrm{MIH}(9-11,14)$ and some limitations can be observed regarding the use of the parental version of questionnaires $(9,11)$, and regarding the collection of children's dental data from records retrieved from the service responsible for care $(9,10)$. Therefore, the aim of this study was to investigate the prevalence of dental fear and to evaluate its association with dental caries and $\mathrm{MIH}$ in schoolchildren aged 8-10 years.

\section{Material and Methods}

\section{Study Design and Location}

This is a cross-sectional study conducted in Campina Grande, PB, Brazil. The city has estimated population of 407,472 inhabitants, Human Development Index (HDI) of 0.72, and Gini Coefficient of 0.58 (15).

\section{Population and Sample Calculation}

Participants were selected from total population of 53,596 schoolchildren (15), regularly enrolled in elementary schools in the municipality of Campina Grande. Cluster sampling was probabilistic and sample size calculation 
was performed considering 26\% prevalence (16), 95\% confidence level, standard deviation of 1.96, 5\% sampling error, and correction factor of 1.4, totaling 414 students. Twenty percent $(20 \%)$ was added to this value to compensate for possible losses, and the final sample was estimated at 518 children. Two public schools were drawn in each of the six selected urban Health Districts (HD), totaling 12 institutions.

\section{Inclusion and Exclusion Criteria}

All 8-10 year-old children who had all first permanent molars fully erupted were included. Exclusion criteria consisted of children with mental retardation or developmental disorders, neuropsychiatric disorders (17) and those with fixed orthodontic appliance.

\section{Training}

Theoretical and practical training of the three examiners was performed by gold standard researchers with previous experiences in epidemiological investigations for the diagnosis of dental caries and $\mathrm{MIH}$. For dental caries, examiners took theoretical training online at https://www. iccms-web.com/ and regarding discussions about clinical diagnosis (18); practical stage was held in a public school. The inter-examiner Kappa correlation values found ranged from 0.80 to 0.90 and intra-examiners values from 0.71 to 0.75 . For $\mathrm{MIH}$, theoretical training implied the clinical presentation and the differential diagnosis condition $(19,20)$, followed by in lux calibration (20). Cohen's Kappa coefficient was from 0.61 to 0.72 for inter-examiner calibration and 0.67 to 0.83 for intra-examiner calibration.

\section{Pilot Study}

A pilot study was conducted to evaluate the methodology, which included forty-nine children for convenience that were not included in the study sample. The results of the pilot study revealed that no changes to the proposed methods were needed.

\section{Data Collection}

Data collection was performed between March and May 2019. The questionnaire developed by researchers contained questions regarding guardians (nuclear family structure when child lived with biological parents who were married or in a stable union, and non-nuclear family structure when the child lived with only one biological parent who was single, divorced or widowed (11), schooling, monthly family income and participation in assistance programs) and children (sex, age, mental retardation or developmental disorders, and neuropsychiatric disorders), in addition to data about their oral health habits (if they visited dentist in life, type of dental health service consulted, dental pain and dental sensitivity in the last 6 months).

The next step consisted of applying the Children's Fear Survey Schedule-Dental Subscale (CFSS-DS) (17) questionnaire, validated for Brazil, which consists of 15 items related to different aspects of dental treatment, whose answers are scored on a five-point scale, from one (not afraid) to five (very afraid), with scores ranging from 15 to 75 . Dental fear was rated as low in children with scores $<32$ and moderate $\geq 32$ and $\leq 38$, but score $>38$ was considered high (17). Children with CFSS-DS $\geq 38$ were defined as having dental fear (17).

Before clinical examination, children were instructed on oral hygiene procedures and received fluoridated toothpaste and toothbrush by means of which their teeth were cleaned by supervised brushing. Clinical examinations took place in a reserved place in the school, under natural light, with the help of headlamps (JWS Lanternas, São Paulo, SP, Brazil). Researchers used all personal protective equipment, mouth mirrors (Golgran Indústria e Comércio de Instrumental Odontológico, São Caetano do Sul, SP, Brasil), WHO probes (Trinity Indústria e Comércio Ltda., São Paulo, SP, Brazil), and gauze, sterilized in autoclave (Gnatus Equipamentos Médico-Odontológicos Ltda., Barretos, SP, Brazil).

Children were evaluated to determine their dental caries experience according to the International Caries Detection and Assessment System II (ICDAS II). Dental caries was considered present for ICDAS code $>0$ and severity was classified as: healthy - code 0 ; early stage codes 1 and 2; moderate stage - codes 3 and 4; advanced stage - codes 5 and 6 (21). MIH diagnosis was based on index proposed by Ghanim et al. (19) and the differential diagnosis of MIH was performed when diffuse opacities, white dental caries spots, amelogenesis imperfecta, enamel hypoplasia and other hypomineralization defects, distinct from $\mathrm{MIH}$, were present (19). MIH was considered present when at least one hypomineralized permanent first molar was found (19). MIH severity was classified as: mild, only color changes - cream, white, yellow, orange or brown and severe - fracture and/or atypical restoration/atypical caries/loss due to MIH (20). Dental caries and MIH severity in each child were defined by the most severe ICDAS code observed in dental elements and the most severe defect observed in first permanent molars and/or permanent incisors, respectively (22).

\section{Statistical Analysis}

Data were analyzed using STATA software (version 15.0 for Windows, StataCorp., College Station, TX, USA). The following variables were dichotomized for statistical analysis purposes: parents or guardians' schooling $(\leq 8$ years of schooling and $>8$ years of schooling, where 8 years 
is equivalent to complete elementary and middle school), dental pain complaint in the last 6 months (yes, no/do not know), dental sensitivity complaint in the last six months (yes, no/do not know) and dental caries severity (early stage for ICDAS 1 and 2 codes and moderate/advanced stage for ICDAS 3-6 codes).

To characterize the sample, descriptive analysis was conducted. The association of the independent variables with dental fear in children was determined using robust Poisson regression analysis for complex samples. All variables with $p<0.2$ in the bivariate analysis were included in the multivariate analysis with the adjustment factors. Prevalence ratios (PR) with their respective $95 \%$ confidence intervals $(95 \% \mathrm{Cl})$ were calculated for the associations. The fit of the model was assessed using the values of the Log pseudolikelihood, Wald Test and Pearson goodness-of-fit. Data overdispersion was assessed using the likelihood ratio (LR) test of overdispersion, which pointed to the absence of significant deviations from the equidispersion pattern. Significance level of 5\% was adopted.

\section{Ethical Considerations}

This study was approved by the Ethics Committee on Research with Human Beings of the State of Paraiba University, under number 3.155.847. Informed consent was obtained from all guardians and individuals included in the study. All study procedures were conducted in accordance with Resolution 466/12 of the National Health Council, Ministry of Health and the Declaration of Helsinki (1964) and its subsequent amendments.

\section{Results}

Of the 518 questionnaires, 35 were excluded due to incomplete data, 6 due to the presence of mental retardation, and 11 due to neuropsychiatric disorders. The final sample consisted of 466 children (89.9\%) with average age of $8.95(\mathrm{Cl} 95 \%=8.87-9.02)$. The average number of affected teeth per child was 4.91 (Cl 95\%=4.57-5.25), and $3.34(\mathrm{Cl} 95 \%=2.73-3.95)$, for dental caries and $\mathrm{MIH}_{\text {, }}$ respectively.

The prevalence of dental fear was $21.6 \%$, and the mean total CFSS-DS score was 29.97 (Cl 95\%=29.05-30.89). According to CFSS-DS, most children had low dental fear (60.6\%); however, 99 (20.9\%) had high dental fear.

Table 1 shows the dental fear distribution according to sociodemographic and oral health variables of children. In the bivariate analysis, dental fear was associated with monthly family income $(p=0.023)$.

Based on estimates of the final model, pseudo likelihood $\log =-813.55545$ (Wald $\chi 2=9.72 ; p=0.0454$ ) was found, indicating that at least one of the tested predictor variables significantly contributed to predict the outcome. Multiple regression model was used to assess associations of variables (Table 2). In the adjusted analysis, the association between dental fear and monthly family income maintained its significance; the prevalence of dental fear was 78\% higher among families receiving monthly income of up to 1 minimum wage $(\mathrm{PR}=1.78 ; \mathrm{Cl} 95 \%=1.02-3.08 ; \mathrm{p}=0.041)$.

\section{Discussion}

The prevalence of children with dental fear deserves attention, as fear generates a cyclical problem (12) in which children are more likely to delay treatment, leading to more severe problems and symptomatic visits, which increase the maintenance or exacerbation of dental fear (12). Another issue is the potential link with non-cooperative behaviors (4), which may lead to increased treatment time, even threatening the dental care outcome (13). Therefore, children with dental fear should be identified to reduce the consequences of the disease and to adopt appropriate approaches.

In the present study, the prevalence of dental fear found was 21.6\% and mean CFSS-DS score was 29.97. This finding is in line with previous studies conducted in Italy (26\%) (16), Brazil (25.79) (17), Greece (27.10) (4) and Nigeria (38.60) (6). However, the score was higher than that reported for Greek (4) and Brazilian (17) children and lower for Nigerian (6) children, in relation to the mean score, which was also lower for Italian (16) children, regarding prevalence. However comparing studies using CFSS-DS and others using different research tools to assess dental fear is difficult due to the diversity of populations, considering differences in cultural aspects, age groups, in methodological issues, sampling methods, and cutoffs established to define dental fear $(1,4,7)$.

The choice of CFSS-DS as instrument for measuring dental fear was due to the fact that the questionnaire is easy to apply, has good internal consistency, high testretest reliability, good criterion validity $(13,17)$ and is widely used in several countries, such as the Netherlands (2), Greece $(4,14)$, Sweden $(9,10)$, China $(13)$, Italy $(16)$, among others. This indicates that CFSS-DS is a reliable instrument for measuring dental fear in children. It is a self-report or parental report questionnaire, and in this research, it was applied directly to children, since it was observed that when using the parental version of the questionnaire, less anxious parents tend to underestimate their children's dental fear, and more anxious parents tend to overestimate it (11). In Brazil, as far as we know, this is the first research that associates dental fear with dental caries and MIH using CFSS-DS.

The classification high of the dental fear rate found in this study, based on the research by Barbério (17), may have occurred due to the socioeconomic context of children, 
because school type is used as an alternative indicator of socioeconomic status, in which children from public schools are considered as a disadvantaged social group (23). Lower socioeconomic condition limits access to high-quality and

Table 1. Bivariate Poisson regression model between dental fear, sociodemographic and oral health variables of children

\begin{tabular}{|c|c|c|c|c|c|c|c|c|}
\hline \multirow{3}{*}{ Variables } & \multicolumn{4}{|c|}{ Dental fear } & \multirow{2}{*}{\multicolumn{2}{|c|}{ Total }} & \multirow{3}{*}{$\mathrm{PR}_{\text {Crude }}(\mathrm{CI}$ 95\%) } & \multirow{3}{*}{$\mathrm{p}$ value } \\
\hline & \multicolumn{2}{|c|}{ Yes } & \multicolumn{2}{|c|}{ No } & & & & \\
\hline & $\mathrm{n}^{(\mathrm{a})}$ & $\% \%^{(b)}$ & $\mathrm{n}^{\text {(a) }}$ & $\% \%^{(b)}$ & $\mathrm{n}^{(\mathrm{a})}$ & $\%($ (b) & & \\
\hline \multicolumn{9}{|l|}{ Sex } \\
\hline Female & 62 & 23.9 & 197 & 76.1 & 259 & 100.0 & $1.27(0.89-1.82)$ & 0.194 \\
\hline Male & 41 & 18.8 & 166 & 81.2 & 207 & 100.0 & 1 & \\
\hline \multicolumn{9}{|l|}{ Age } \\
\hline 8 & 36 & 20.2 & 134 & 79.8 & 170 & 100.0 & 1 & \\
\hline 9 & 38 & 21.9 & 129 & 78.1 & 167 & 100.0 & $1.08(0.71-1.65)$ & 0.703 \\
\hline 10 & 29 & 23.0 & 100 & 77.0 & 129 & 100.0 & $1.14(0.73-1.77)$ & 0.568 \\
\hline \multicolumn{9}{|l|}{ Family Structure } \\
\hline Not nuclear & 45 & 21.7 & 150 & 78.3 & 195 & 100.0 & 1 & \\
\hline Nuclear & 55 & 21.4 & 205 & 78.6 & 260 & 100.0 & $1.01(0.71-1.45)$ & 0.940 \\
\hline \multicolumn{9}{|l|}{ Schooling of parents/guardians } \\
\hline$\leq 8$ years of schooling & 56 & 21.8 & 201 & 78.2 & 257 & 100.0 & $1.03(0.72-1.48)$ & 0.871 \\
\hline$>8$ years of schooling & 43 & 21.1 & 151 & 78.9 & 194 & 100.0 & 1 & \\
\hline \multicolumn{9}{|l|}{ Monthly family income } \\
\hline Up to 1 minimum wage ${ }^{(c)}$ & 67 & 18.6 & 282 & 81.4 & 349 & 100.0 & $1.61(1.07-2.44)$ & $0.023^{*}$ \\
\hline More than 1 minimum wage ${ }^{(c)}$ & 23 & 30.0 & 55 & 70.0 & 78 & 100.0 & 1 & \\
\hline \multicolumn{9}{|l|}{ Receives financial benefit ${ }^{(\mathrm{d})}$} \\
\hline Yes & 59 & 22.6 & 192 & 77.4 & 251 & 100.0 & 1 & \\
\hline No & 42 & 20.3 & 167 & 79.7 & 209 & 100.0 & $1.12(0.78-1.60)$ & 0.552 \\
\hline \multicolumn{9}{|l|}{ Visited the dentist some time in life } \\
\hline Yes & 57 & 20.0 & 226 & 80.0 & 283 & 100.0 & 1 & \\
\hline No & 45 & 23.9 & 134 & 76.1 & 179 & 100.0 & $1.20(0.84-1.71)$ & 0.324 \\
\hline \multicolumn{9}{|l|}{ Type of dental health service consulted } \\
\hline Public & 33 & 17.3 & 153 & 82.7 & 186 & 100.0 & $1.45(0.88-2.37)$ & 0.143 \\
\hline Private & 21 & 25.0 & 65 & 75.0 & 86 & 100.0 & 1 & \\
\hline \multicolumn{9}{|l|}{ Dental pain in the last 6 months } \\
\hline Yes & 46 & 23.2 & 151 & 76.8 & 197 & 100.0 & $1.14(0.80-1.62)$ & 0.479 \\
\hline No/ Don’t know & 55 & 20.4 & 207 & 79.6 & 262 & 100.0 & 1 & \\
\hline \multicolumn{9}{|l|}{ Dental sensitivity in the last 6 months } \\
\hline Yes & 44 & 23.3 & 144 & 76.7 & 188 & 100.0 & $1.14(0.80-1.63)$ & 0.472 \\
\hline No/Don’t know & 58 & 20.4 & 215 & 79.6 & 273 & 100.0 & 1 & \\
\hline \multicolumn{9}{|l|}{ Dental caries (ICDAS >0) } \\
\hline Present & 98 & 23.1 & 316 & 76.9 & 414 & 100.0 & $2.32(0.97-5.51)$ & 0.057 \\
\hline Absent & 5 & 10.0 & 47 & 90.0 & 52 & 100.0 & 1 & \\
\hline \multicolumn{9}{|l|}{ Severity of dental caries } \\
\hline Initial stage (ICDAS 1 and 2) & 5 & 13.4 & 28 & 86.6 & 33 & 100.0 & 1 & \\
\hline Moderate/advanced stage (ICDAS 3-6) & 93 & 24.0 & 288 & 76.0 & 381 & 100.0 & $1.79(0.75-4.25)$ & 0.189 \\
\hline \multicolumn{9}{|l|}{$\mathrm{MIH}$} \\
\hline Present & 15 & 27.0 & 41 & 73.0 & 56 & 100.0 & $1.29(0.80-2.09)$ & 0.297 \\
\hline Absent & 88 & 20.9 & 322 & 79.1 & 410 & 100.0 & 1 & \\
\hline \multicolumn{9}{|l|}{ Severity of the MIH } \\
\hline Mild & 11 & 29.9 & 26 & 70.1 & 37 & 100.0 & 1 & \\
\hline Severe & 4 & 21.3 & 15 & 78.7 & 19 & 100.0 & $0.71(0.25-2.00)$ & 0.521 \\
\hline
\end{tabular}

(a) Non-weighted estimates; ${ }^{(b)}$ Weighted estimates considering the complex sampling plan. ${ }^{\text {(c) }}$ Brazilian minimum wage in force at the time of the research equivalent to US \$ 264; (d) Family government benefit (Welfare); PR=prevalence ratio; CI=confidence interval; * $\mathrm{p}<0.05$. 
regular dental treatment options for children in Brazil (17).

It is recognized that socioeconomic status is considered an indirect influence on dental fear $(5,8)$. The factors experienced by the child are considered direct influences (5), such as caries (6) and dental pain $(5,11)$, as well as previous history of dental treatment $(5,8,24)$. In this research, significant association between dental fear and monthly family income was found, but some other studies have found no association $(4,11)$. This significant association, with prevalence of dental fear being $78 \%$ higher among children living on an income of up to 1 Brazilian minimum wage, may be related to the fact that children from lower socioeconomic levels visit the dentist less, probably due to the lower purchasing power, which can help maintaining or increasing dental fear (8). The socioeconomic level is a strong marker for health indicators, in which individuals from lower socioeconomic levels exhibit worse general and oral health conditions (25).

In addition, study with children from different socioeconomic levels found higher average CFSS-DS score among those with lower income and differences in the level of dental fear due to socioeconomic level (SES) (26), according to the Rachman's theory (27). Modeling (learning through the observation of "models", such as parents or siblings) was the main responsible for predicting dental fear in low-income children; however, direct conditioning (learning by the child) was the predictor in children with high socioeconomic level (26). Thus, it could be inferred that when family members with lower socioeconomic status have negative attitudes towards dental stimuli, the child may develop dental fear (28). Parents' dental fear can also affect a child's previous dental history, resulting in delayed treatment, which can increase the likelihood of

Table 2. Multiple Poisson regression model between dental fear and independent variables

\begin{tabular}{|c|c|c|c|c|}
\hline \multirow{2}{*}{ Variables } & \multicolumn{2}{|c|}{ Bivariate } & \multicolumn{2}{|c|}{ Multivariate $e^{(e)}$} \\
\hline & $\mathrm{PR}_{\text {Crude }}(\mathrm{CI}$ 95\%) & $\mathrm{p}$ value & $\mathrm{PR}_{\text {Adjusted }}(\mathrm{CI}$ 95\%) & $\mathrm{p}$ value \\
\hline \multicolumn{5}{|l|}{ Sex } \\
\hline Female & $1.27(0.89-1.82)$ & 0.194 & $1.30(0.78-2.19)$ & 0.316 \\
\hline Male & 1 & & 1 & \\
\hline \multicolumn{5}{|l|}{ Monthly family income } \\
\hline Up to 1 minimum wage $\mathrm{e}^{(f)}$ & $1.61(1.07-2.44)$ & $0.023^{*}$ & $1.78(1.02-3.08)$ & $0.041^{*}$ \\
\hline More than 1 minimum wage $e^{(f)}$ & 1 & & 1 & \\
\hline \multicolumn{5}{|c|}{ Type of dental health service consulted } \\
\hline Public & $1.45(0.88-2.37)$ & 0.143 & $1.29(0.75-2.21)$ & 0.361 \\
\hline Private & 1 & & 1 & \\
\hline \multicolumn{5}{|l|}{ Dental caries (ICDAS > 0) } \\
\hline Present & $2.32(0.97-5.51)$ & 0.057 & $1.59(0.58-4.31)$ & 0.367 \\
\hline Absent & 1 & & 1 & \\
\hline
\end{tabular}

$\mathrm{PR}=$ prevalence ratio; $\mathrm{CI}=$ confidence interval; ${ }^{*} \mathrm{p}<0.05$. (e) Model adjusted by the following co-variables: sex, monthly family income, type of dental health service consulted, and dental caries. (f) Brazilian minimum wage in force at the time of the research equivalent to US \$ 264. painful or traumatic treatment (28). Children with better economic condition, on the other hand, by acquiring fear through direct conditioning and by having greater opportunity for a more appropriate treatment with less probability of resulting in a conditioning event, may develop dental fear less quickly than children without such conditions.

No significant associations were found between dental fear, dental caries and $\mathrm{MIH}$, corroborating with previous researches $(9-11,14)$. Only in the study by Menoncin et al. (11), dental caries experience in primary teeth was associated with lower levels of dental fear, compared to the absence of dental caries. In this case, children may possibly understand that the dentist can alleviate their pain, so that they do not fear dental treatment.

The relationship between dental fear and dental caries is controversial $(4-6,8)$. Children with dental fear have worse oral health conditions (5) because poor oral health increases the likelihood of dental pain, or can result in a negative dental experience (7), which can reinforce the occurrence of dental fear (5). Although the percentage of children who reported dental fear was significantly higher among those with dental caries, it could be inferred that these children were possibly influenced by other factors such as cultural $(1,4,5)$ and psychosocial $(7)$ as well as the socioeconomic condition itself $(5,8)$. Another factor is the ICDAS sensitivity, where dental caries, if in the chronic phase (17), may not influence dental fear reports. The diversity of study methodologies, including differences in the age range of the sample (4-7) and data analysis methodologies (6), may explain these differences. In addition, it can be interpreted as a possibility, that the higher frequency of dental caries of moderate/advanced severity among children with dental fear are consequences of the vicious cycle of fear, in which individuals with dental fear avoid treatment, leading to the progression of disease, reinforcing fear (12).

A possible explanation for the lack of association between dental fear and MIH stems from the fact that the prevalence of this type of fear tends to be lower in older children, when compared with younger ones (11), and, according to Menoncin et al. (11), this may also explain the lack of association found in previous studies $(9,10,14)$. The severity of MIH is another issue that must be considered to explain this finding, since lesions with only color changes, as found in higher number in this 
research, have less clinical implications compared to more severe ones (11). Teeth severely affected by MIH require restorations due to enamel disintegration and the possibility of developing dental caries (9), which can promote painful symptoms as a result of difficulties in anesthesia, probably due to subclinical inflammation of pulp cells caused by enamel porosity (20). As a consequence, these children may experience fear during dental treatment (9).

Some limitations can be observed in this study, such as the impossibility of investigating the cause-andeffect relationship, since this study has cross-sectional design. On the other hand, as strengths we can cite the generalization of results for the target population, the use of a validated questionnaire, the execution of a pilot study, the performance of clinical examinations by trained researchers, and the self-report of dental fear by children. This research provides relevant epidemiologic data for the design of future studies, thus providing the best clinical management strategies during dental care.

In conclusion, monthly family income is associated with dental fear in children, whereas dental caries and $\mathrm{MIH}$ are not associated with dental fear. Dental fear is widely recognized for its detrimental effects and identifying children with this condition helps to control dental fear by influencing oral health improvement.

\section{Resumo}

0 objetivo deste estudo foi investigar a prevalência de medo odontológico e avaliar sua associação com a cárie dentária e a Hipomineralização molar-incisivo (HMI), em escolares de 8 a 10 anos, em um município da região Nordeste do Brasil. Foram coletados dados de 466 estudantes matriculados em escolas públicas urbanas, em um estudo transversal. Os pais/responsáveis responderam a um questionário abordando caracteristicas sociodemográficas, o medo odontológico foi mensurado por meio do Children's Fear Survey Schedule-Dental Subscale (CFSS-DS), e os exames clínicos foram realizados por três examinadores calibrados para o diagnóstico de cárie dentária, utilizando o indice International Caries Detection \&t Assessment System (ICDAS II) e, por um indice previamente validado, para HMI. Foi realizada a análise descritiva dos dados e as associações entre medo odontológico, cárie dentária e HMI foram avaliadas pela regressão robusta de Poisson para amostras complexas $(p<0,05)$. A prevalência de medo odontológico foi de $21,6 \%$, e o escore médio total do CFSS-DS foi de 29,97 (IC 95\%=29,05-30,89). No modelo multivariado ajustado, a prevalência de medo odontológico esteve associada à renda familiar $(\mathrm{RP}=1,78$; IC $95 \%=1,02-3,08$; $\mathrm{p}=$ 0,041 ). A renda familiar mensal foi associada ao medo odontológico em crianças, enquanto a cárie dentária e a $\mathrm{HMI}$ não foram associadas ao medo odontológico.

\section{Acknowledgements}

This work was supported by Coordination for the Advancement of Higher Education Personnel (CAPES) (Financing Code 001), National Council for Scientific and Technological Development (CNPq) Research Productivity Scholarship (Process Number 302850/2016-3) and the State of Paraiba Research Assistance Foundation (FAPESO/PB) (concession term 021/2018, Protocol 005/2018 - SEIRHMACT/FAPESQ/ $\mathrm{PB})$, Brazil. The authors thank Colgate-Palmolive Company for donating oral hygiene kits.

\section{References}

1. Klingberg G, Broberg AG. Dental fear/anxiety and dental behaviour management problems in children and adolescents: a review of prevalence and concomitant psychological factors. Int J Paediatr Dent 2007;17:391-406.

2. Krikken JB, Vanwijk AJ, Tencate JM, Veerkamp JS. Child dental anxiety, parental rearing style and dental history reported by parents. Eur J Paediatr Dent 2013;14:258-262.

3. Abanto J, Vidigal EA, Carvalho TS, Sá SN, Bönecker M. Factors for determining dental anxiety in preschool children with severe dental caries. Braz Oral Res 2017;31:e13.

4. Boka V, Arapostathis K, Karagiannis V, Kotsanos N, van Loveren C, Veerkamp J. Dental fear and caries in 6-12 year old children in Greece. Determination of dental fear cut-off points. Eur J Paediatr Dent 2017;18:45-50.

5. Torriani DD, Ferro RL, Bonow ML, Santos IS, Matijasevich A, Barros AJ, et al. Dental caries is associated with dental fear in childhood: findings from a birth cohort study. Caries Res 2014;48:263-70.

6. Folayan MO, Kolawole KA, Onyejaka NK, Agbaje HO, Chukwumah NM, Oyedele TA. General anxiety, dental anxiety, digit sucking, caries and oral hygiene status of children resident in a semi-urban population in Nigeria. BMC Oral Health 2018;18:66.

7. Ten Berge M, Veerkamp JS, Hoogstraten J. The etiology of childhood dental fear: the role of dental and conditioning experiences. J Anxiety Disord 2002;16:321-329.

8. Barreto KA, Dos Prazeres LD, Lima DS, Soares FC, Redivivo RM, da Franca $C$, et al. Factors associated with dental anxiety in Brazilian children during the first transitional period of the mixed dentition. Eur Arch Paediatr Dent 2017;18:39-43.

9. Jälevik B, Klingberg GA. Dental treatment, dental fear and behaviour management problems in children with severe enamel hypomineralization of their permanent first molars. Int J Paediatr Dent 2002;2:24-32.

10. Jälevik B, Klingberg G. Treatment outcomes and dental anxiety in 18-year-olds with $\mathrm{MIH}$, comparisons with healthy controls: a longitudinal study. Int J Paediatr Dent 2012;22:85-91.

11. Menoncin BLV, Portella PD, Ramos BLM, Assunção LRDS, de Souza JF, Menezes JVNB. Dental anxiety in schoolchildren with molar incisor hypomineralization-A population-based cross-sectional study. Int J Paediatr Dent 2019;29:615-623.

12. Armfield JM, Stewart JF, Spencer JÁ. The vicious cycle of dental fear: exploring the interplay between oral health, service utilization and dental fear. BMC Oral Health 2007;7:1.

13. $M a L$, Wang $M$, Jing $Q$, Zhao J, Wan $K, X u \quad O$. Reliability and validity of the chinese version of the children's fear survey schedule-dental subscale. Int J Paediatric Dent 2015;5:110-116.

14. Kosma I, Kevrekidou A, Boka V, Arapostathis K, Kotsanos N. Molar incisor hypomineralisation (MIH): correlation with dental caries and dental fear. Eur Arch Paediatr Dent 2016;17:123-129.

15. Brazilian Institute of Geography and Statistics (IBGE). Brasil/Paraiba/ Campina Grande. Panorama [Internet]. Available from: https://cidades. ibge.gov.br/brasil/pb/campina-grande/panorama [Latest Access October 15, 2020].

16. Caprioglio A, Mariani L, Tettamanti L. A pilot study about emotional experiences by using CFSS-DS in young patients. Eur J Paediatr Dent 2009;10:121-124.

17. Barbério GS. Reliability and validity of the Brazilian version of the Children's Fear Survey Schedule-Dental Subscale questionnaire for assessing fear and anxiety about dental treatment in children. PhD thesis - Bauru School of Dentistry, University of São Paulo, Bauru. 2017.

18. Pitts N. "ICDAS" - an international system for caries detection and assessment being developed to facilitate caries epidemiology, research and appropriate clinical management. Community Dent Health 2004;21:193-198.

19. Ghanim A, Mariño R, Manton DJ. Validity and reproducibility testing of the Molar Incisor Hypomineralisation (MIH) Index. Int J Paediatr Dent 2019;29:6-13. 
20. Ghanim A, Silva MJ, Elfrink MEC, Lygidakis NA, Mariño RJ, Weerheijm $\mathrm{KL}$, Manton DJ. Molar incisor hypomineralisation $(\mathrm{MIH})$ training manual for clinical field surveys and practice. Eur Arch Paediatr Dent 2017:18:225-242.

21. Pitts NB, Ismail Al, Martignon S, Ekstrand K, Douglas GVA, Longbottom $\mathrm{C}$ and contributing co-authors on behalf of the Participating Authors of the International Caries Classification and Management System (ICCMSTM) Implementation Workshop, held June 2013, 2014. ICCMSTM Guide for Practitioners and Educators. \{Internet\}. Available from: https://www.iccms-web.com/content/resources/iccms-icdaspublications [Latest Access October 15, 2020].

22. Gambetta-Tessini $K$, Mariño $R$, Ghanim $A$, Calache $H$, Manton DJ. The impact of MIH/HSPM on the carious lesion severity of schoolchildren from Talca, Chile. Eur Arch Paediatr Dent 2019;20:417-423.

23. Piovesan C, Padua MC, Ardenghi TM, Mendes FM, Bonini GC. Can type of school be used as an alternative indicator of socioeconomic status in dental caries studies? A cross-sectional study. BMC Med Res Methodol 2011;11:37.
24. Cademartori MG, Rosa DP, Brancher LC, Costa VPP, Goettems ML. Association of dental anxiety with psychosocial characteristics among children aged 7-13 years. Pesqui Bras Odontopediatria Clín Integr 2020;20:e4635.

25. Silveira ERD, Goettems ML, Demarco FF, Azevedo MS. Clinical and individual variables in children's dental fear: a school-based investigation. Braz Dent J 2017;28:398-404.

26. Lin YL, Yen YY, Chen HS, Liu YC, Chang CS, Chen CM, et al. Child dental fear in low-income and non-low-income families: A school-based survey study. J Dent Sci 2014;9:165-171.

27. Rachman $S$. The conditioning of fear acquisition: a critical examination. Behav Res Ther 1977;5:375-387.

28. Seligman LD, Hovey JD, Chacon K, Ollendick TH. Dental anxiety: An understudied problem in youth. Clin Psychol Rev 2017;55:25-40.

Received March 30, 2020 Accepted September 25, 2020 